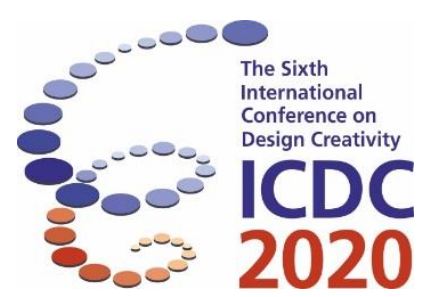

\title{
Co-Design Visions of Public Makerspaces in China
}

\author{
Busayawan Lam ${ }^{1}$, Youngo $\mathrm{Choi}^{1}$, Xi Chen ${ }^{1}$, Sophia de Sousa ${ }^{2}$, Long \\ Liu, ${ }^{3}$ and Minqing $\mathrm{Ni}^{3}$ \\ ${ }^{1}$ Design Department, Brunel University London, United Kingdom \\ ${ }^{2}$ The Glass-House Community Led Design, London, United Kingdom \\ ${ }^{3}$ College of Design and Innovation, Tongji University, Shanghai, China
}

\begin{abstract}
This paper discusses the design and outputs of co-design workshops used to facilitate the co-creation of a shared vision for public makerspaces in China and the design of such space. The workshops were held with Chinese and non-Chinese participants to identify similarities and differences in terms of approaches, outputs and key considerations. Initial results suggested that these workshops were effective at supporting value co-creation, as they excel at engaging participants and enable them to collaborate as equal partners. It was observed that Chinese participants were rather pragmatic and conscious of sustainable growth.
\end{abstract}

Keywords: co-design, makerspaces, value co-creation

\section{Introduction}

This paper explores the application of collaborative design or co-design in the context of placemaking. It discusses the design and principal findings of three sets of co-design workshops carried out as part of the project titled Fostering Creative Citizens through Co-design and Public Makerspaces. In this case, public makerspace is defined as "a physical location where people gather to co-create, share resources and knowledge, work on projects, network, and build. They help intermediate and advance users develop their skills and creativity, particularly inspiring younger generations to engage with the STEM agenda - Science, Technology, Engineering and Mathematics" (Department for Digital, Culture, Media and Sport, 2017). The users of makerspaces are generally referred to as makers.

The overall goal is to develop a novel and inclusive means of fostering creative citizens in China in a bottom-up manner through strategic use of co-design and public makerspaces. The rationale is that the collaborative and sharing nature of public makerspaces could enable individual and collective creativity to flourish. The paper presents the results from the first phase of this project.

The overall research plan follows the structure of the 'Double Diamond' model developed by the Design Council, UK (2005) and all key activities match four main stages in the model. The first phase can be described as the Discover and Define stages, since it aims to 1) identify key requirements of public makerspaces and community creative hubs in China, as well as main drivers and potential barriers; and 2) seek insights from best practices of physical and virtual creative communities. The study began with literature review and case studies to identify good practices from creative communities in the UK and other countries. Simultaneously, interviews were conducted with different stakeholders in China to capture requirements regarding public makerspaces. Furthermore, field trips were organised to provide first-hand experience of public makerspaces in the UK to key stakeholders from China. At 
the end of the first phase, the research team shared principal findings with key stakeholders and organised co-design workshops to help them co-create shared visions for public makerspace in China. This paper also explores how Chinese people perceive making and public makerspace by comparing their shared visions with those from other cultures.

\section{Background Research}

The literature review begins with the investigation of the co-creation process followed by the review of potential co-design tools that could be used to create strategic outputs, such as shared visions. Finally, the context where the tools will be applied - Chinese perceptions toward making and public makerspace - will be discussed. In this way, suitable activities, that could help different stakeholders better understand each other and co-create shared visions of public makerspace, could be identified.

\subsection{The Co-creation Process for Strategic Development}

The co-creation process has increasingly been used to generate strategic outputs, such as visions, strategies and value propositions. For example, Pralahad and Ramaswamy (2004a) advised companies to co-create value with customers, since this practice could lead to many benefits, such as enabling indepth dialogue between companies and customers; increasing customers' inputs in the development process, which could lead to better product quality; and enhancing transparency. The authors urged companies to think innovatively about the co-creation experience, as it has significant impact on the quality of the process and its outputs. To effectively use co-creation experience as the basis for value co-creation, Pralahad and Ramaswamy (2004b) proposed four building blocks of interactions: Dialogue, Access, Risk-benefits and Transparency (or DART). In this case, dialogue refers to twoways conversations between companies and customers, while access and transparency suggest that organisations should give customers access to information they need that could help fuel honest and productive dialogues as well as realistic risk-benefits assessments of their collaborative work.

Similar suggestions were made by Roser and Samson (2009) who described co-creation as "an active, creative and social process, based on collaboration between producers and users, that is initiated by the firm to generate value for customers". According to Ramaswamy and Gouillart (2010), enterprises that employ a co-creative strategy with an intention to serve all stakeholders could achieve advantages through the increased engagement of stakeholders, which could help them respond better in rapidly changing markets. By continually building new interactions and experiences, the firms could get higher productivity, higher creativity, higher satisfactions (from staff and customers), and lower costs and risks (ibid). Since value co-creation can be defined as "one or more form(s) of value(s) produced through the collective creativity of people" (Sanders and Simons, 2012), it is not exclusively applied to the commercial sector. The public and voluntary sectors could also use this collaborative approach to cocreate services with users - see Szebeko and Tan (2010) for an example.

\subsection{The Co-design Tools for Strategic Development}

An increase of interest in co-creating strategic outputs generates opportunities for co-design, as it could assist different stakeholders in sharing ideas and working collectively to achieve mutual goals. For example, Kleinsmann (2006) described co-design as "the process in which actors from different disciplines share their knowledge about both the design process and the design content. They do that in order to create shared understanding on both aspects, to be able to integrate and explore their knowledge and to achieve the larger common objective." While co-design is commonly used to create tangible outputs, such as new products, it could support the development of strategic outputs. This is because the co-design process enables all parties to share and combine knowledge in order to develop a shared understanding (Steen, 2013). For instance, the Western Australian Council of Social Services recommended co-design as a means to developing and delivering community services in partnership with citizens. Moreover, the sharing of skills and experience of various participants could lead to novel solutions (Mattelmaki, 2008) as well as improvements in various areas, e.g. processes of idea generation, decision-making, customer satisfaction and loyalty over the long-term (Steen, 2011). 
Brandt, Binder and Sanders (2012) suggested that the co-design process comprises of three key activities: Telling, Making and Enacting. Although these three activities do not directly match the building blocks of value co-creation, they share some common principles. For instance, telling, which focuses on sharing stories, is described as a key driver of active participation in the same way that dialogue is considered a starting point of value co-creation. While Pralahad and Ramaswamy's model emphasises on access and transparency of information, the co-design process concentrates on how information shared among different partners could be used to generate useful results, since the co-design process is outcome-based with a practical focus (Bradwell and Marr, 2008). The act of making is used to visualise ideas, while enacting is employed to demonstrate how their ideas would work. These activities enable all parties to exchange information, thoughts and ideas effectively - in other words, enable in-depth dialogue and support them in investigating potential risk-benefits. There are many types of tools that could be used to support the act of telling, making and enacting. Different types of tools and their purposes can be summarised as shown in Table 1 and 2 below.

Table 1. The tools and techniques organized by form and by purpose

\begin{tabular}{|c|c|c|c|c|c|}
\hline \multicolumn{2}{|c|}{ Tools and Techniques } & Probe & Prime & Understand & Generate \\
\hline \multirow{3}{*}{$\begin{array}{l}\text { Making } \\
\text { Tangible } \\
\text { Things }\end{array}$} & $\begin{array}{l}\text { 2-D Collages using visual and verbal triggers on } \\
\text { backgrounds with timelines, circles, etc. }\end{array}$ & $\checkmark$ & $\checkmark$ & $\checkmark$ & $\checkmark$ \\
\hline & $\begin{array}{l}\text { 2-D Mappings using visual and verbal } \\
\text { components on patterned backgrounds }\end{array}$ & & $\checkmark$ & $\checkmark$ & $\checkmark$ \\
\hline & $\begin{array}{l}\text { 3-D Mock-ups using e.g. foam, clay, Legos or } \\
\text { Velcro-modelling }\end{array}$ & & & $\checkmark$ & $\checkmark$ \\
\hline \multirow{2}{*}{$\begin{array}{l}\text { Talking, } \\
\text { Telling } \\
\text { and } \\
\text { Explaining }\end{array}$} & $\begin{array}{l}\text { Diaries and daily logs through writing, drawing, } \\
\text { blogs, photos, video, etc. }\end{array}$ & $\checkmark$ & $\checkmark$ & $\checkmark$ & \\
\hline & $\begin{array}{l}\text { Cards to organize, categorize and prioritize ideas. } \\
\text { The cards may contain video snippets, incidents, } \\
\text { signs, traces, moments, photos, domains, } \\
\text { technologies, templates and what if provocations }\end{array}$ & & & $\checkmark$ & $\checkmark$ \\
\hline \multirow{5}{*}{$\begin{array}{l}\text { Acting, } \\
\text { Enacting } \\
\text { and } \\
\text { Playing }\end{array}$} & $\begin{array}{l}\text { Game boards and game pieces and rules for } \\
\text { playing }\end{array}$ & & $\checkmark$ & $\checkmark$ & $\checkmark$ \\
\hline & Props and black boxes & & & $\checkmark$ & $\checkmark$ \\
\hline & $\begin{array}{l}\text { Participatory envisioning and enactment by } \\
\text { setting users in future situations }\end{array}$ & & & & $\checkmark$ \\
\hline & Improvisation & & & & $\checkmark$ \\
\hline & Acting out, skits and play acting & & & $\checkmark$ & $\checkmark$ \\
\hline
\end{tabular}

Source: Sanders, Brandt and Binder (2010)

In order to co-create shared visions for the public makerspace, different stakeholders need to exchange information, value and ideas, as well as negotiate and agree on a strategic direction that reflects requirements of all parties. Hence, the co-design workshop in this study must be robust enough to encompass all three key activities and require various types of co-design tools to support them.

\subsection{The Concept of Making in China}

Since visions of public makerspace are based on how Chinese people perceive making and makerspace, it was critical to investigate the making culture in Chinese society. Most discourse of making in China is often related to two basic ideas: Crafting and Manufacturing. The former concept can be described as a nostalgia for craft culture. This type of making is generally organised in a bottom-up manner. However, it only appeals to certain groups (e.g. the middle-class urban dwellers, who would like to escape from their busy reality). Through handcrafting activities, people feel as if they could return to a time where working with one's hands was a necessity. This sentiment is expressed in the makerspace literature of both the US and China (Irie, Hsu and Ching, 2019). In this sense, public makerspaces are perceived as a leisure place, where people pay for crafting activities.

In contrast, the manufacturing aspect of making is advocated through a top-down manner. Chinese government considers making as a way of promoting "mass innovation" and "entrepreneurship". This 
reflects a shift of economic mode from "Made in China" to "Designed in China". For example, in 2015, Chinese Premier Li Keqiang visited Chaihuo Makerspace in Shenzhen. He praised the innovation generated by makers and considered makerspaces to be a driving force for China's economic growth (Xie, 2018). In an attempt to spread the ideas of mass innovation, the Chinese government also promotes creative spaces for entrepreneurs to prototype and build their businesses (Saunders and Kingsley, 2016). As a result, makerspaces in China are often created as start-up factories where people can work with technology on real problems like air/water pollution (Saunders and Kingsley, 2016). The idea of the general public using makerspaces is not well documented.

Table 2. Current applications of the tools and techniques described by context

\begin{tabular}{|c|c|c|c|c|c|}
\hline \multicolumn{2}{|c|}{ Current Applications of the Tools and Techniques } & Individual & Group & Face-to-face & Online \\
\hline \multirow{3}{*}{$\begin{array}{l}\text { Making } \\
\text { Tangible } \\
\text { Things }\end{array}$} & $\begin{array}{l}\text { 2-D Collages using visual and verbal triggers on } \\
\text { backgrounds with timelines, circles, etc. }\end{array}$ & $\checkmark$ & $\checkmark$ & $\checkmark$ & $\checkmark$ \\
\hline & $\begin{array}{l}\text { 2-D Mappings using visual and verbal } \\
\text { components on patterned backgrounds }\end{array}$ & $\checkmark$ & $\checkmark$ & $\checkmark$ & $\checkmark$ \\
\hline & $\begin{array}{l}\text { 3-D Mock-ups using e.g. foam, clay, Legos or } \\
\text { Velcro-modelling }\end{array}$ & $\checkmark$ & $\checkmark$ & & $\checkmark$ \\
\hline \multirow{2}{*}{$\begin{array}{l}\text { Talking, } \\
\text { Telling } \\
\text { and } \\
\text { Explaining }\end{array}$} & $\begin{array}{l}\text { Stories and storyboarding through writing, } \\
\text { drawing, blogs, wikis, photos, video, etc. }\end{array}$ & $\checkmark$ & $\checkmark$ & $\checkmark$ & \\
\hline & $\begin{array}{l}\text { Diaries and daily logs through writing, drawing, } \\
\text { blogs, photos, video, etc. }\end{array}$ & & $\checkmark$ & $\checkmark$ & $\checkmark$ \\
\hline \multirow[t]{5}{*}{$\begin{array}{l}\text { Acting, } \\
\text { Enacting } \\
\text { and } \\
\text { Playing }\end{array}$} & $\begin{array}{l}\text { Cards to organize, categorize and prioritize ideas. } \\
\text { The cards may contain video snippets, incidents, } \\
\text { signs, traces, moments, photos, domains, } \\
\text { technologies, templates and what if provocations }\end{array}$ & $\checkmark$ & $\checkmark$ & & $\checkmark$ \\
\hline & $\begin{array}{l}\text { Game boards and game pieces and rules for } \\
\text { playing }\end{array}$ & $\checkmark$ & $\checkmark$ & & $\checkmark$ \\
\hline & Props and black boxes & $\checkmark$ & $\checkmark$ & & $\checkmark$ \\
\hline & $\begin{array}{l}\text { Participatory envisioning and enactment by } \\
\text { setting users in future situations }\end{array}$ & $\checkmark$ & $\checkmark$ & & $\checkmark$ \\
\hline & Improvisation & $\checkmark$ & $\checkmark$ & & $\checkmark$ \\
\hline
\end{tabular}

Source: Sanders, Brandt and Binder (2010)

\section{Co-design Workshop: Design by Consensus}

This section introduces the Design by Consensus workshop, which was used as a basis for the co-design workshops in this study. This workshop was chosen because it addressed the majority of the building blocks of strategic co-creation and co-design activities (see Figure 1). The workshop was originated by The Glass-House Community Led Design in 2006. The initial aim was to create a session that could bring together different disciplines across different sectors to explore challenges and opportunities of engaging multiple stakeholders the design of a public space. It was designed to be provocative, to spark discussion and debate, as well as provide an immersive and interactive experience. It contains two main activities: role playing and co-creation. Participants are expected to work together to create a mutual vision for an imagined site and the design of such space.

\begin{tabular}{|c|c|c|c|}
\hline \multirow[b]{2}{*}{ Purposes } & \multirow{2}{*}{$\begin{array}{c}\text { Role-playing } \\
\begin{array}{c}\text { Building empathy \& } \\
\text { understanding }\end{array}\end{array}$} & \multicolumn{2}{|c|}{ Co-creation } \\
\hline & & $\begin{array}{c}\text { Developing the shared } \\
\text { vision for the site }\end{array}$ & $\begin{array}{l}\text { Creating the design } \\
\text { for the site }\end{array}$ \\
\hline $\begin{array}{r}\text { Links to co-design } \\
\text { activities }\end{array}$ & TELLING & \multicolumn{2}{|c|}{ MAKING \& ENACTING } \\
\hline $\begin{array}{l}\text { Links to building } \\
\text { blocks of co-creation }\end{array}$ & DIALOGUE & \multicolumn{2}{|c|}{ DIALOGUE + RISK-BENEFITS ASSESSMENT } \\
\hline
\end{tabular}

Figure 1. The overall structure of the co-design workshop 
For the role-play task, participants are divided into groups (of 5-15 people). They are asked to step into various stakeholder roles (e.g. resident groups and local businesses) and represent them. Various role cards describing the requirements of different stakeholders are given to participants to help them understand their roles. For the co-creation task, they are asked to work together to 1) map their shared and conflicting interests, concerns and aspirations, and 2) negotiate a shared vision for the site.

Asking participants to step into roles and negotiate an imagined site (in which they have no vested interest or connections) is an important part of this workshop, as it allows them to focus on the process itself, and to do so in a playful and neutral environment. The process helps emphasise that, despite conflicting interests, different stakeholders actually share some fundamental values and aspirations. Through this process, participants are able to build empathy and understanding of each other.

The co-creation task requires participants to map very simple design ideas and urge them to consider: how and when people would use the space; what materials might be used; how the space would be enlivened/managed/maintained; etc. It also encourages participants to explore the 'design' with and for multiple and diverse users. The workshop has been used in various contexts, with communities, design and regeneration professionals, students, researchers and policy makers. It was even used as a framework for helping multiple research partners co-design a collaborative action research project.

\section{Design by Consensus Workshop for Public Makerspace}

Within the context of this research project, the Design by Consensus workshop was adapted by The Glass-House to explore the co-design of public makerspaces. The brief on this occasion was to create a workshop to help people come together to explore how they could shape a building to cater for multiple different makers, and to be a space that could help engage the community in creative making activities. The workshop activity and accompanying resources would need to spark discussion and debate about the functionality of the space, the type of atmosphere it would create, and its social and economic purpose. As the workshop would be conducted with Chinese participants and those from different backgrounds, it was essential that the props should be as visual and accessible as possible, and not rely heavily on written text. A series of roles were created to represent potential stakeholders of public makerspaces, such as a start-up business, a knitting group, a digital maker, and a facility manager. These roles can be broadly categorised into three groups: 1) building staff; 2) experienced or professional makers who needed regular workspace; and 3) occasional or aspiring makers with varying degrees of experience. As in the original workshop, the participants were divided into groups and allocated stakeholder roles. They were also asked to co-create a shared vision of the makerspace based on different needs and interests of various stakeholders and the ideal design of such space.

The workshops began with the presentation of preliminary research results to help participants develop a better understanding of makerspaces in China and other countries. Next, they were briefed about the tasks and assigned different roles. Participants were given a floorplan of an imagined building, as well as a series props to help them explore various types of the space, e.g. shared and private workspaces, clean and messy, quiet and noisy, storage and social spaces (see Figure 2). The props also included some standard building features (such as kitchens, toilets, doors, windows and corridors). Finally, participants were asked to present their vision statements and the design to other teams.

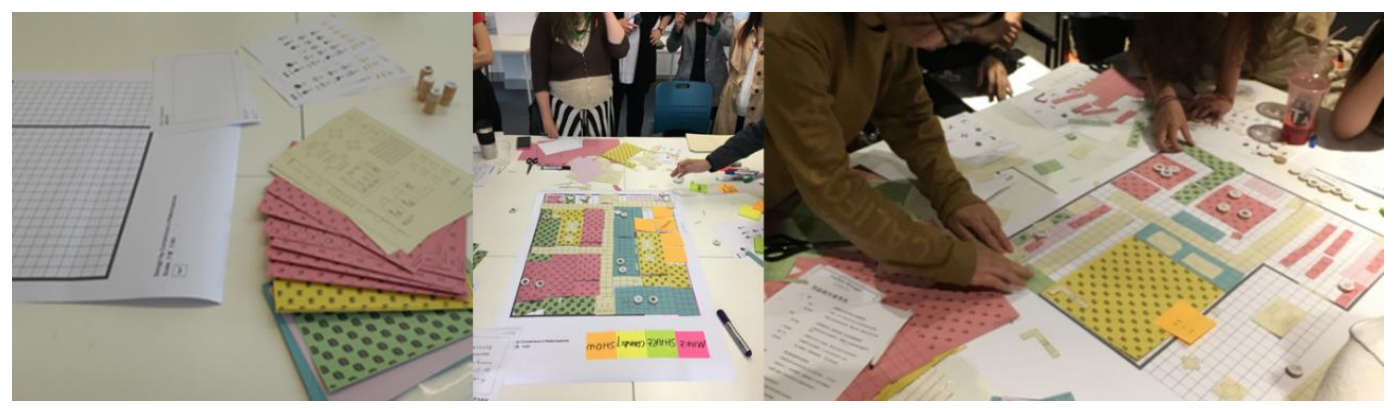

Figure 2: An imagined building with props for different types of space 
The co-design workshops were conducted three times in both the UK and China (1st and 3rd workshops were conducted in the UK, and 2nd workshop was organised in China). Across these workshops, eight groups of participants (8-12 per group) took part in this study: Groups 1-6 contained only Chinese participants; Group 7 had participants from other Asian countries (e.g. Thailand, India and South Korea); and Group 8 had participants from Western countries (e.g. Greece and Brazil). All workshops had the same structure. They lasted two hours followed by a 5 minutes short presentation from each group. The participants came from various backgrounds: university students, academics, artists, local residents, designers and businesspersons. These led to eight outputs (see Figure 3).

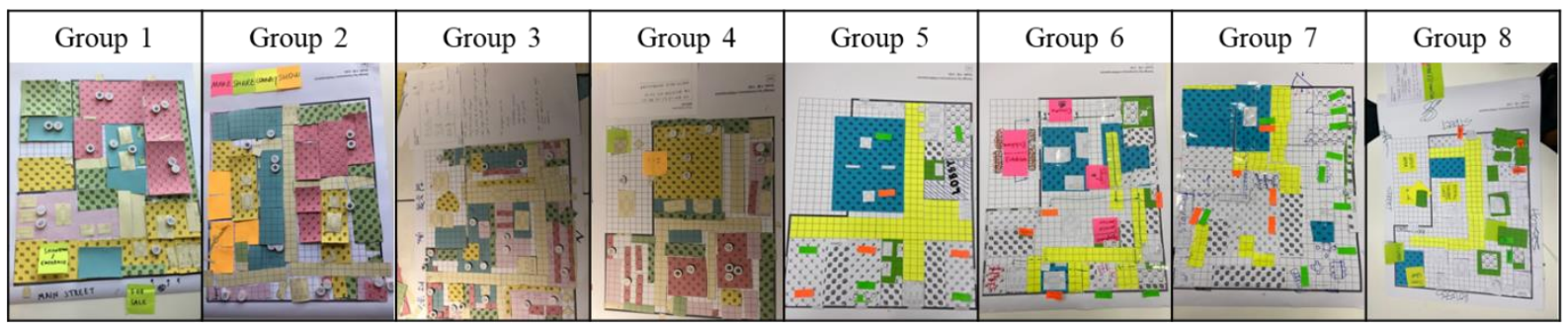

Figure 3. The outputs from three workshops created by eight groups of participants

\section{Discussions \& Conclusion}

The research found that there are some similarities and differences between Chinese and non-Chinese groups in terms of the vision statements and main consideration on the space design.

\subsection{Similarities}

All groups believed that interactions between makers and non-makers (e.g. local residents) were crucial when designing public makerspaces. Thus, most groups decided to make 'making activities' visible to the general public through windows, which could generate a sense of welcome. Moreover, most participants preferred to have some exhibition space inside and/or outside of the building, where the items made in the makerspace can be displayed (or sold with expectations of economic value creation). Most participants believed that making should be perceived as an 'inclusive' activity that is accessible for everyone. Hence, they would like to place their makerspaces in a residential area in order to maximise opportunities for interacting with local people. In this way, non-makers could develop interests in making and become makers in the future. All groups separated the workspaces based on the functionality and organised the areas according to the level of noise - e.g. placing a noisy handcraft workspace in a large shared space in one corner of the building, and locating a quiet digital work zone in an opposite corner. Having a garden (e.g. a green space) appeared to be important to all groups. Generally, most participants wanted to maintain a reasonable level of privacy. Hence, in most cases, a wooden fence was used to block the garden area from the public.

\subsection{Differences}

Chinese groups displayed differences in terms of 1) the design process, 2) spatial planning strategy, 3) perceptions towards making and socialising, and 4) considerations for economic sustainability. Further details of their considerations on the physical environments are summarised in Figure 4.

Firstly, in terms of the design process, it was observed that all Chinese groups spent a relatively small amount of time (5 - 10 minutes) on a strategic task (the development of shared vision). In most cases, they quickly brainstormed and agreed on the common ideas in an efficient manner. They spent a larger amount of time on a practical task (the design of the space), e.g. negotiating the requirements of each stakeholder. On the contrary, the non-Chinese groups spent a larger amount of time (15-20 minutes) on the development of shared vision. They appeared to be more flexible with the design of the space. For example, most participants did not mind if some of their requirements were not met.

Secondly, certain elements of control were observed in the spatial planning strategy of some Chinese participants. For instance, four out of six Chinese groups decided to keep the outdoor space mainly for the makers, which makes it easier to control and managed. Chinese participants were quite optimistic 
about future growth and anticipated that there would be an increasing number of makers. Hence, they prepared a relatively large workspace in anticipation for more members. In contrary, Western participants did not envision a significant increase of makers and would be satisfied with relatively small workspace. Creating a productive working environment was also the main concern of Chinese teams. Two Chinese groups emphasised the importance of separating workspace into the private and public zones. The rationale was that they preferred to work efficiently in their private areas without any disruptions from visitors. The productivity concern was not observed in non-Chinese groups.

\begin{tabular}{|c|c|c|c|c|c|c|c|c|c|}
\hline & \multirow{2}{*}{$\begin{array}{l}\text { Location } \\
\text { Group } \\
\text { Number }\end{array}$} & \multicolumn{2}{|c|}{$1^{\text {st }}$ Workshop, UK } & \multicolumn{2}{|c|}{$2^{\text {nd }}$ Workshop, China } & \multicolumn{4}{|c|}{$3^{\text {rd }}$ Workshop, UK } \\
\hline & & Group 1 & Group 2 & Group 3 & Group 4 & Group 5 & Group 6 & Group 7 & Group 8 \\
\hline \multirow[t]{3}{*}{$\begin{array}{l}\text { Vision } \\
\text { Statement }\end{array}$} & Process & \multicolumn{6}{|c|}{ Quick discussion. (5-10 minutes). } & \multicolumn{2}{|c|}{$\begin{array}{l}\text { Long discussion }(15-20 \\
\text { minutes })\end{array}$} \\
\hline & \multirow[t]{2}{*}{ Result } & \multicolumn{6}{|l|}{ Key words } & \multicolumn{2}{|c|}{ Detailed sentences } \\
\hline & & $\begin{array}{l}\text { Theme } \\
\text { park of } \\
\text { Making }\end{array}$ & $\begin{array}{l}\text { Make, } \\
\text { share, } \\
\text { connect, } \\
\text { show }\end{array}$ & $\begin{array}{l}\text { Cosy, } \\
\text { variety, } \\
\text { inclusive, } \\
\text { stories. }\end{array}$ & $\begin{array}{l}\text { Relaxing } \\
\text { workplace } \\
\text { for } \\
\text { professional } \\
\text { making }\end{array}$ & $\begin{array}{l}\text { A } \\
\text { welcoming } \\
\text { space }\end{array}$ & $\begin{array}{l}\text { Entertaining } \\
\text { and } \\
\text { sustainable }\end{array}$ & $\begin{array}{l}\text { Boundless } \\
\text { space to } \\
\text { collaborate } \\
\text { and share } \\
\text { experience }\end{array}$ & $\begin{array}{l}\text { Inclusive } \\
\text { space for } \\
\text { socialising } \\
\text { and skill } \\
\text { development }\end{array}$ \\
\hline \multirow{10}{*}{$\begin{array}{l}\text { Spatial } \\
\text { Strategy }\end{array}$} & \multirow[t]{2}{*}{ Layout } & \multicolumn{8}{|c|}{ Organised around noise level and messy versus clean areas. } \\
\hline & & $\begin{array}{l}\text { Separated } \\
\text { private } \\
\text { and } \\
\text { public } \\
\text { zones }\end{array}$ & $\mathrm{N} / \mathrm{A}$ & $\begin{array}{l}\text { Separated } \\
\text { private } \\
\text { and } \\
\text { public } \\
\text { zones }\end{array}$ & $\mathrm{N} / \mathrm{A}$ & $\mathrm{N} / \mathrm{A}$ & N/A & $\mathrm{N} / \mathrm{A}$ & N/A \\
\hline & \multirow[t]{3}{*}{ Social space } & \multicolumn{4}{|c|}{ Several small internal areas } & \multicolumn{4}{|c|}{ One large internal area } \\
\hline & & \multicolumn{7}{|c|}{ Extended to the external space. } & $\mathrm{N} / \mathrm{A}$ \\
\hline & & Shop & Shop & Shop & Shop & N/A & Shop & N/A & Coffee shop \\
\hline & \multirow[t]{2}{*}{ Work space } & \multicolumn{8}{|c|}{$\begin{array}{l}\text { Shared space and storage for connection and working together. Based on the natures of different making activities, } \\
\text { e.g., the handcrafting works and digital works are separated. }\end{array}$} \\
\hline & & \multirow{2}{*}{\multicolumn{6}{|c|}{$\begin{array}{l}\text { Led by the objective of making it a positive and productive working environment } \\
\text { Mainly social space. } \\
\text { Some include a few storage and exhibition area }\end{array}$}} & \multicolumn{2}{|c|}{$\begin{array}{l}\text { Some prefer to work in } \\
\text { social areas. }\end{array}$} \\
\hline & \multirow[t]{3}{*}{$\begin{array}{l}\text { External } \\
\text { space }\end{array}$} & & & & & & & $\begin{array}{l}\text { Work } \\
\text { space }\end{array}$ & Green Area \\
\hline & & $\begin{array}{l}\text { Makers } \\
\text { only }\end{array}$ & $\begin{array}{l}\text { Makers } \\
\text { and the } \\
\text { public }\end{array}$ & Makers onl & & & $\begin{array}{l}\text { Makers and } \\
\text { the public }\end{array}$ & $\begin{array}{l}\text { Makers } \\
\text { only }\end{array}$ & $\begin{array}{l}\text { Makers and } \\
\text { the public }\end{array}$ \\
\hline & & $\begin{array}{l}\text { Accessed } \\
\text { only } \\
\text { through } \\
\text { the } \\
\text { building }\end{array}$ & $\begin{array}{l}\text { Accessed } \\
\text { from } \\
\text { outside } \\
\text { of the } \\
\text { building }\end{array}$ & Accessed o & ly through the & uilding & $\begin{array}{l}\text { Accessed } \\
\text { from } \\
\text { outside of } \\
\text { the building }\end{array}$ & $\begin{array}{l}\text { Accessed } \\
\text { only } \\
\text { through the } \\
\text { building }\end{array}$ & $\begin{array}{l}\text { Accessed } \\
\text { from outside } \\
\text { of the } \\
\text { building }\end{array}$ \\
\hline \multirow[t]{2}{*}{ Context } & $\begin{array}{l}\text { Role of } \\
\text { Makerspace } \\
\text { in the } \\
\text { Community }\end{array}$ & \multicolumn{2}{|c|}{$\begin{array}{l}\text { To welcome and } \\
\text { engage the public in } \\
\text { creative making } \\
\text { activities. }\end{array}$} & \multicolumn{2}{|c|}{$\begin{array}{l}\text { To focus on those already } \\
\text { doing it }\end{array}$} & \multicolumn{3}{|c|}{$\begin{array}{l}\text { To welcome and engage the public in } \\
\text { creative making activities. }\end{array}$} & $\mathrm{N} / \mathrm{A}$ \\
\hline & $\begin{array}{l}\text { Purpose of } \\
\text { Makerspace }\end{array}$ & \multicolumn{3}{|c|}{$\begin{array}{l}\text { A space for connection; both for the } \\
\text { makers within the building and for } \\
\text { connecting the public }\end{array}$} & $\begin{array}{l}\text { To support } \\
\text { professional } \\
\text { makers }\end{array}$ & N/A & $\begin{array}{l}\text { Multi- } \\
\text { function }\end{array}$ & $\mathrm{N} / \mathrm{A}$ & $\begin{array}{l}\text { To support } \\
\text { professional } \\
\text { makers }\end{array}$ \\
\hline
\end{tabular}

Figure 4: Comparison of workshop outputs

Thirdly, their perceptions toward making and socialising might be slightly different. In the western literature, making and socialising are interconnected - see Taylor, Hurley and Connolly (2016) for an example. However, socialisation might not be seen as part of 'making' from Chinese participants' perspectives. Although having a proper socialising space for makers were important to all groups, the Chinese groups preferred to separate a socialising space from a making space. In contrast, the Western group combined making with socialising areas, as they believed that it would be more enjoyable and meaningful way of making. It was observed that all Chinese groups tended to use the outdoor space for socialisation, which created a clear separation between socialising and making.

Finally, most Chinese participants demonstrated strong business awareness by considering economic sustainability of the makerspace. Five out of six Chinese groups introduced a shop in order to sell the artefacts produced by the makers. Generating incomes was not included in the requirements of the 
workshops. This idea was proposed by Chinese participants themselves. In contrast, the Western Group introduced a café in the building, mainly for relaxing - not for a commercial reason.

Even with a small sample size, it can be seen that Chinese and non-Chinese participants might perceive public makerspaces differently. Chinese participants appeared to be more pragmatic in a way that they co-created the design whilst the other groups paid more attention on the shared visions of the space. The outcomes of these co-design workshops have helped the research team identify design considerations that were rarely discussed in western literature, e.g. productivity, element of control, and a separation between socialising and making. However, the results revealed more common requirements than previously thought, e.g. interests in public engagement.

The model of a co-design workshop based on role-play, and with a series of tactile props, is easily adaptable to a range of contexts, as has been evidenced by the variety of contexts in which the Design by Consensus workshop has already been used. It serves as an introduction to the co-design principles and process through the narrative of the particular task introduced in the workshop, and to provide a frame that participants can adapt and apply to their own co-design task. The application of the Design by Consensus in this project suggested that these co-design workshops were effective at supporting value co-creation, as they excel at engaging participants and enable them to collaborate as equal partners. While cultural differences emerged in the outputs developed by Chinese participants and those from other cultures, it supported an accessible and inclusive way to introduce participants to the codesign of their makerspaces, and to explore and articulate their shared values and design ambitions.

\section{References}

Bradwell, P., \& Marr, S. (2008). Making the most of collaboration: An international survey of public service codesign. London: Demos.

Brandt, E., Binder, T. \& Sanders, E. (2012). Tools and techniques: Ways to engage telling, making and enacting. In Simonsen, J. and Robertson T. (Eds.), Routledge International Handbook of Participatory Design (pp. 145-181). London: Routledge International Handbooks.

Design Council (2007). Eleven Lessons: Managing Design in Eleven Global Companies. [online] Design Council. Available at: https://www.designcouncil.org.uk/resources/report/11-lessons-managing-design-globalbrands (Accessed: 10/11/19).

Department for Digital, Culture, Media and Sport (2017) Guidance: Libraries and makerspaces. [online] HM Government. Available at: https://www.gov.uk/government/publications/libraries-and-makerspaces/librariesand-makerspaces (Accessed: 25/02/18)

Irie, R. N., Hsu, Y. \& Ching, Y. (2019). Makerspaces in diverse places: a comparative analysis of distinctive national discourses surrounding the maker movement and education in four countries. Tech Trends, 63 (4) 397407.

Kleinsmann, M. S. (2006). Understanding collaborative design [Thesis], Delft University of Technology. Mattelmäki, T. (2008). Probing for co-exploring. Co-Design, 4 (1), 65-78.

Prahalad, C.K. \& Ramaswamy, V. (2004a), Co-creating unique value with customers. Strategy and Leadership, 32(3), 4-9.

Prahalad, C.K. \& Ramaswamy, V. (2004b). Co-creation Experiences: The Next Practice in Value Creation. Journal of Interactive Marketing, 18(3), 5-14.

Ramaswamy, V. \& Gouillart, F. (2010). Building the Co-Creative Enterprise. Harvard Business Review, 88(10), 100-109.

Roser, T. \& Samson, A. (2009). Co-creation: New pathways to value: An overview. [online] Promise / LSE Enterprise. Available at: https://www.researchgate.net/publication/272566751_Co-

creation_New_Pathways_to_Value_An_Overview (Accessed: 10/11/19).

Sanders, E. \& Simons, G. (2012). A Social Vision for Value Co-creation in Design. [online] Open Source Business Resource. Available at: http://www.osbr.ca/ojs/index.php/osbr/article/view/1012/973 (Accessed: 10/11/19).

Sanders, E., Brandt, E. \& Binder, T. (2010). A Framework for Organizing the Tools and Techniques of Participatory Design, In Proceedings of PDC 2010 / 11 th Biennial Participatory Design Conference, Sydney, Australia, November 29 - December 3, 2010, ACM, New York, pp. 195-198.

Saunders, T. \& Kingsley, J. (2016). Made in China: Makerspaces and the search for mass innovation. London: NESTA.

Steen, M. (2013). Co-Design as a Process of Joint Inquiry and Imagination. Design Issues, 29(2), 16-28. 
Steen, M., Manschot, M. and Koning, N. (2011). Benefits of Co-Design in Service Design Projects.

International Journal of Design, 5(2), 53-60.

Szebeko, D. \& Tan, L. (2010). Co-designing for Society. Australasian Medical Journal, 3(9), 580-590.

Taylor, N., Hurley, U. and Connolly, P. (2016) Making Community: The Wider Role of Makerspaces in Public Life. ACM

Xie, Y. (2018). Made in China: The Boom and Bust of Makerspaces. [online] SIXTH TONE. Available at: https://www.sixthtone.com/news/1003171/made-in-china-the-boom-and-bust-of-makerspaces (accessed: $11 / 11 / 19)$ 